\title{
Proceeding
}

Supplementary Issue: Spring Conferences of Sports Science. 15th Convention and Workshop of the International Network of Sport and Health Science, 5-8 June 2019. University of Las Palmas de Gran Canaria, Las Palmas de Gran Canaria, Spain.

\section{Energy expenditure and weight loss with aerobic exercise: A longitudinal study in young adults}

\author{
ISMAEL GALVEZ ${ }^{1} \triangle$, JOSÉ CARLOS FERNÁNDEZ GARCÍA', JUAN GAVALA GONZÁLEZ² \\ ${ }^{1}$ University of Malaga, Malaga, Spain \\ 2University of Seville, Seville, Spain
}

\begin{abstract}
The objective of this study was to analyse the amount of time young adults spent performing vigorous, moderate intensity activities, walking and sitting through the International Physical Activity Questionnaire Short Form (IPAQ-SF), as well as the loss of weight and fat mass before and after an aerobic training program. The sample consisted of 20 men aged $21.86 \pm 1.85$ years who initially had a body mass index $(\mathrm{BMl})>25 \mathrm{~kg} / \mathrm{m} 2$. The training program was carried out for twelve weeks, three times per week on nonconsecutive days, in sessions lasting 60 to 90 minutes. Before and after the treatment, an anthropometric assessment of weight, height and fat mass was performed using a dual-energy $\mathrm{x}$-ray densitometry equipment and the participants were also asked to complete the IPAQ-SF questionnaire. The results showed a statistically significant improvement in both weight ( $88.29 \mathrm{vs} 86.52) \mathrm{kg}, \mathrm{BMl}(29.22 \mathrm{vs} 28.64) \mathrm{kg} / \mathrm{m} 2$ and body fat (26.43 vs 25.21) kg. Similarly, energy expenditure (METS min/week) improved in all measurements: in vigorous (980.87 vs 4038.26 ) and moderate physical activity (450.44 vs 1615.65$)$, walking (949.25 vs $1336.50)$ and total (2380.56 vs 6690.42$)$, although no significant differences in energy consumed walking were found. The main conclusion reached after this research is that in young adults who are overweight or obese, an exclusively aerobic exercise program, enabled them to reduce their body weight by approximately the same amount of fat mass lost and that their adherence to physical exercise increased as their moderate and vigorous levels increased nearly fourfold, and their total physical activity was more than double that at the beginning of the program. Keywords: Overweight; Obesity; Aerobic training; IPAQ-SF.
\end{abstract}

\section{Cite this article as:}

Galvez, I., Fernández, J.C., \& Gavala, J. (2019). Energy expenditure and weight loss with aerobic exercise: A longitudinal study in young adults. Journal of Human Sport and Exercise, 14(4proc), S713S723. doi:https://doi.org/10.14198/ihse.2019.14.Proc4.32

Corresponding author. University of Malaga, Malaga, Spain. https://orcid.org/0000-0002-6923-9779

E-mail: ismaelgalf@uma.es

Supplementary Issue: Spring Conferences of Sports Science. 15th Convention and Workshop of the International Network of Sport and Health Science, 5-8 June 2019. University of Las Palmas de Gran Canaria, Las Palmas de Gran Canaria, Spain. JOURNAL OF HUMAN SPORT \& EXERCISE ISSN 1988-5202

(c) Faculty of Education. University of Alicante

doi:10.14198/jhse.2019.14.Proc4.32 


\section{INTRODUCTION}

Overweight and obesity are defined as an abnormal or excessive accumulation of fat that can be harmful to health and are associated with the risk of developing comorbidities such as diabetes mellitus, hypertension, metabolic syndrome, cardiovascular disease and cancer (Drenowatz et al. 2017; Ostendorf et al., 2017). Body mass index (BMI) is a simple indicator of the relationship between weight and height that is frequently used to identify overweight and obesity in adults. BMI is calculated by dividing weight in kilos by the square of height in meters. The World Health Organization (WHO) establishes a Body Mass Index (BMl) of 18.5 to $24.9 \mathrm{~kg} / \mathrm{m}^{2}$ for normal weight, 25 to $29.9 \mathrm{~kg} / \mathrm{m}^{2}$ for overweight, and $30 \mathrm{~kg} / \mathrm{m}^{2}$ and above for obesity (WHO, 2019).

The WHO defines physical activity as any bodily movement produced by skeletal muscles, with the consequent consumption of energy. This includes activities performed while working, playing and travelling, doing household chores and engaging in recreational activities. Energy expenditure (EE) represents the energy consumed by the body and consists of the sum of the basal metabolic rate, endogenous thermogenesis and physical activity (PA) (Rodríguez et al, 2018). Most studies associate food intake and physical activity with modification of EE (Jakicic et al. 2015); (Swendeman et al. 2018), or even with energy intake alone (Drenowatz et al 2017; Ostendorf et al., 2017). However, in our study we focused only on the PA variable, through a twelve-week aerobic training (AT) program, to assess whether there was a change in $\mathrm{EE}$, body weight, BMI and the amount of body fat.

The most commonly used instruments for determining PA include objective tools such as pedometers, accelerometers, calorimeters and gas analysers, or indirect instruments such as questionnaires. The latter are widely used in public health studies due to their low cost and ease of application (Rojas-Gómez et al, 2018).

The International Physical Activity Questionnaire (IPAQ) has been validated at the international level (Craig et al. 2003) and is supported by the WHO. Studies by Nielson et al. (2008) show that only two out of 23 physical activity questionnaires, including the IPAQ, have acceptable validation criteria, as the differences between their means are between $2 \%$ and $10 \%$. The version used in this research was the International Physical Activity Questionnaire - Short Form (IPAQ-SF). This questionnaire consists of seven questions about the frequency, duration and intensity of activity (moderate and vigorous) carried out in the previous seven-day period, as well as walking and sitting during a workday. Weekly activity is recorded in METs (Metabolic Equivalent of Task) per minute and week (Carrera, 2017). In addition, this questionnaire in its short version has been used in several intervention studies in adults with satisfactory results (Guedes, 2007; Pitsavos et al., 2008; Bull et al., 2009; Lee et al., 2011; Vanhelst, 2013; Chor et al., 2016).

Data obtained from the IPAQ-SF can be converted into METs. In this way, we obtained information that allowed us to determine the number of weekly METS consumed both before and after intervention treatment with AT, as has been done in similar studies (Moseng et al., 2014; Sanda et al., 2017).

A MET is defined as the metabolic rate at rest, that is, the amount of oxygen consumed at rest, sitting quietly in a chair, and is given a value of $3.5 \mathrm{ml} \cdot 0_{2} / \mathrm{kg} / \mathrm{min}(1.2 \mathrm{kcal} / \mathrm{min}$ for a person of $70 \mathrm{~kg})$. Therefore, working at two METS requires twice the metabolism at rest or $7.0 \mathrm{ml} \cdot \mathrm{O}_{2} / \mathrm{kg} / \mathrm{min}$ and three METS requires three times the metabolism at rest $\left(10.5 \mathrm{ml} \cdot \mathrm{O}_{2} / \mathrm{kg} / \mathrm{min}\right.$ ), and so on (Jetté et al., 1990). 
The innovative nature of our study is that until now no literature has been available on the treatment of overweight and obesity in young male adults who undertake an exclusively aerobic exercise program, nor has the amount of physical activity or the modification of energy expenditure been measured through IPAQSF with these conditioning factors, thus the singularity of this study.

\section{MATERIALS AND METHODS}

\section{Design and participants}

The sample consisted of a total of 20 young male adults between the ages of 18 and 25 (21.86 \pm 1.85 years), classified according to their BMl, calculated from the reported weight and height. In order to participate in the REPHASO (Rejecting overweight and obesity through healthy habits) research project, the participants had to have a BMI $\geq 25 \mathrm{~kg} / \mathrm{m}^{2}$, as anything above this threshold is considered overweight by the WHO (WHO, 2019).

Participants were recruited from a variety of sources, including advertisements on social networks, advertisements placed on bulletin boards located in university campus buildings and publications on the project website. Participants completed an online form and were selected based on their height and weight to determine BMI. Once selected, they met with the project coordinator who explained the nature of the study, indicating that anonymity would be preserved at all times. The ethical considerations of Sport and Exercise Science Research (Harriss, Macsween, and Atkinson, 2017) were followed, as well as the principles included in the Declaration of Helsinki (JAVA, 2013), which defines the ethical guidelines for research on human subjects and requires the consent of each of the participants prior to participation in the study. Similarly, throughout the intervention and thereafter, action was taken in accordance with the Spanish regulations contained in Organic Law 15/1999, of 13 December, on the protection of personal data.

\section{Instruments}

A Tanita model BC730 scale was used to weigh the participants, and a portable SECA model 213 stadiometer was used to measure height. A dual-energy x-ray densitometer (DXA, Hologic Explorer, United States) was used to evaluate body fat. In addition, the IPAQ-SF was administered.

\section{Procedures}

Each participant was given an initial assessment, in which they were weighed and measured to determine their BMI. Whole-body densitometry was performed to determine the amount of total body fat. They then completed the IPAQ-SF in the form of a self-administered survey.

Once the initial evaluation was completed, the participants were prescribed a twelve-week aerobic training program (Table 1). The program comprised three days of training each week, with each session lasting approximately one and a half hours. The sessions were monitored by a personal trainer who supervised both the volume and intensity of the sessions. Participants who failed to complete at least $90 \%$ of the sessions were excluded from the study. The training period was divided into three stages, which increased in intensity and were regulated according to the subjective rate of perceived exertion (RPE) of the participants, based on the Börg scale (1982). After completing the twelve-week experimental phase of the training, the participants were re-evaluated with the same procedure carried out in the initial evaluation. 
Table 1. Design of the aerobic training program during the experimental phase

\begin{tabular}{|c|c|c|c|c|}
\hline Cycle & Week & & Content & Börg \\
\hline \multirow{12}{*}{1} & \multirow{3}{*}{1} & 1 & $\begin{array}{l}10^{\prime} \text { warm up }+5^{\prime} \text { continuous running }+5^{\prime} \text { walking }+10^{\prime} \text { stretching }+5^{\prime} \\
\text { continuous running }+15^{\prime} \text { walking }+10^{\prime} \text { stretching }\end{array}$ & \multirow{8}{*}{$5-6$} \\
\hline & & 2 & 5' warm up + 50' cycling + 10' stretching & \\
\hline & & 3 & $\begin{array}{l}10^{\prime} \text { warm up }+5^{\prime} \text { continuous running }+5 \text { ' walking }+10^{\prime} \text { stretching }+5^{\prime} \\
\text { continuous running }+15^{\prime} \text { walking }+10^{\prime} \text { stretching }\end{array}$ & \\
\hline & \multirow{3}{*}{2} & 1 & 5 ' warm up + 50' cycling + 10' stretching & \\
\hline & & 2 & $\begin{array}{l}10^{\prime} \text { warm up }+10^{\prime} \text { continuous running }+5^{\prime} \text { walking }+5^{\prime} \text { stretching }+10^{\prime} \\
\text { continuous running }+15^{\prime} \text { walking }+10^{\prime} \text { stretching }\end{array}$ & \\
\hline & & 3 & $5^{\prime}$ warm up + 60' cycling + 10' stretching & \\
\hline & \multirow{3}{*}{3} & 1 & $\begin{array}{l}10 \text { ' warm up }+15 \text { ' continuous running }+10 \text { ' walking }+15^{\prime} \text { continuous running } \\
\text { (finishing at very low intensity) }+10 \text { ' stretching }\end{array}$ & \\
\hline & & 2 & 5' warm up + 60' cycling + 10' stretching & \\
\hline & & 3 & $\begin{array}{l}10^{\prime} \text { warm up }+15 \text { ' continuous running }+10 \text { ' walking }+15^{\prime} \text { continuous running } \\
\text { (finishing at very low intensity) }+10^{\prime} \text { stretching }\end{array}$ & \multirow{4}{*}{$6-7$} \\
\hline & \multirow{3}{*}{4} & 1 & 5' warm up + 70' cycling + 10' stretching & \\
\hline & & 2 & $\begin{array}{l}15^{\prime} \text { warm up }+15^{\prime} \text { continuous running }+5 \text { ' walking }+15^{\prime} \text { continuous running } \\
+10^{\prime} \text { stretching }\end{array}$ & \\
\hline & & 3 & Meeting Days & \\
\hline \multicolumn{5}{|c|}{ Observations: All tasks are performed on terrain with no incline. "Cycling" is bicycling. } \\
\hline Cycle & Week & & Content & Börg \\
\hline \multirow{11}{*}{2} & \multirow{3}{*}{1} & 1 & $\begin{array}{l}10^{\prime} \text { warm up }+5^{\prime} \text { continuous running }+5^{\prime} \text { walking (with a gradient) }+10^{\prime} \\
\text { stretching }+5 \text { ' continuous running }+15^{\prime} \text { walking (if possible, } 10^{\prime} \text { with a } \\
\text { gradient and the last } 5 \text { ' gently with no gradient) }+10^{\prime} \text { stretching }\end{array}$ & \multirow{8}{*}{$6-7$} \\
\hline & & 2 & $\begin{array}{l}\text { 5' warm up }+50 \text { ' cycling (if possible, intersperse with gradients, no more than } \\
8^{\prime} \text { on a gradient) }+10^{\prime} \text { stretching }\end{array}$ & \\
\hline & & 3 & $\begin{array}{l}10^{\prime} \text { warm up }+5 \text { ' continuous running }+5 \text { ' walking (with a gradient) }+10^{\prime} \\
\text { stretching }+5^{\prime} \text { continuous running }+15^{\prime} \text { walking }\left(10^{\prime} \text { with a gradient and the }\right. \\
\text { last } 5 \text { ' gently with no gradient) }+10^{\prime} \text { stretching }\end{array}$ & \\
\hline & \multirow{3}{*}{2} & 1 & 5' warm up + 50' cycling (10' with a gradient) + 10' stretching & \\
\hline & & 2 & $\begin{array}{l}10^{\prime} \text { warm up }+10^{\prime} \text { continuous running ( } 5^{\prime} \text { with a gradient) }+5^{\prime} \text { walking (with } \\
\text { no gradient) }+5 \text { ' stretching }+10^{\prime} \text { continuous running ( } 5^{\prime} \text { with a gradient) }+15^{\prime} \\
\text { walking (with no gradient }+10^{\prime} \text { stretching }\end{array}$ & \\
\hline & & 3 & $5^{\prime}$ warm up + 60' cycling (15' with a gradient) + 10' stretching & \\
\hline & \multirow[t]{3}{*}{3} & 1 & $\begin{array}{l}10^{\prime} \text { warm up }+10^{\prime} \text { continuous running (intersperse with gradients) }+10^{\prime} \\
\text { walking (with no gradient) }+15^{\prime} \text { continuous running (intersperse with } \\
\text { gradients, finishing at very low intensity) }+10^{\prime} \text { stretching }\end{array}$ & \\
\hline & & 2 & 5' warm up + 50' cycling (20' with a gradient) + 10' stretching & \\
\hline & & 3 & Meeting days in the Pavilion at the University of Malaga & \multirow{3}{*}{$7-8$} \\
\hline & \multirow[t]{2}{*}{4} & 1 & $\begin{array}{l}10^{\prime} \text { warm up }+15^{\prime} \text { continuous running (10' with a gradient) }+5^{\prime} \text { walking (on } \\
\text { flat terrain, if possible) }+15^{\prime} \text { continuous running (the first } 5^{\prime} \text { with a gradient, } \\
\text { finishing at very low intensity) }+10^{\prime} \text { stretching }\end{array}$ & \\
\hline & & 2 & $5^{\prime}$ warm up $+60^{\prime}$ cycling (25' with a gradient) $+10^{\prime}$ stretching & \\
\hline
\end{tabular}




\begin{tabular}{|c|c|c|c|c|}
\hline & & 3 & $\begin{array}{c}10^{\prime} \text { warm up }+20^{\prime} \text { continuous running (10' with a gradient) }+5^{\prime} \text { walking (with } \\
\text { no gradient })+20^{\prime} \text { continuous running (the first } 5 \text { ' with a gradient, finishing at } \\
\text { very low intensity) }+10^{\prime} \text { stretching }\end{array}$ & \\
\hline \multicolumn{5}{|c|}{ Observations: the slope or gradient of the terrain should not exceed $5 \%$. } \\
\hline Cycle & Week & & Content & Börg \\
\hline \multirow{12}{*}{3} & \multirow{3}{*}{1} & 1 & $\begin{array}{l}10^{\prime} \text { warm up }+5 \text { ' continuous running }+5^{\prime} \text { walking (with a gradient) }+5 \text { ' } \\
\text { continuous running }+15^{\prime} \text { walking ( } 10^{\prime} \text { with a gradient and the last } 5 \text { ' gently } \\
\text { with no gradient })+10^{\prime} \text { stretching }\end{array}$ & \multirow{12}{*}{$7-8$} \\
\hline & & 2 & $\begin{array}{l}5^{\prime} \text { warm up }+50^{\prime} \text { cycling (intersperse with gradients, con un total de } 15^{\prime} \text { with } \\
\text { a gradient) }+10^{\prime} \text { stretching }\end{array}$ & \\
\hline & & 3 & $\begin{array}{l}10^{\prime} \text { warm up }+5^{\prime} \text { continuous running }+5^{\prime} \text { walking (with a gradient) }+5^{\prime} \\
\text { continuous running }+15^{\prime} \text { walking }\left(10^{\prime} \text { with a gradient and the last } 5^{\prime} \text { with no }\right. \\
\text { gradient })+10^{\prime} \text { stretching }\end{array}$ & \\
\hline & \multirow{3}{*}{2} & 1 & $\begin{array}{l}5^{\prime} \text { warm up }+50^{\prime} \text { cycling }\left(15^{\prime} \text { with no gradient }+20^{\prime} \text { with a gradient }+15^{\prime} \text { with }\right. \\
\text { no gradient })+10^{\prime} \text { stretching }\end{array}$ & \\
\hline & & 2 & $\begin{array}{l}10^{\prime} \text { warm up }+10^{\prime} \text { continuous running (if possible, } 5^{\prime} \text { on a gradient) }+5^{\prime} \\
\text { walking (on flat terrain, if possible) }+10^{\prime} \text { continuous running }\left(5^{\prime} \text { with a }\right. \\
\text { gradient, if possible })+15^{\prime} \text { walking (with no gradient) }+10^{\prime} \text { stretching }\end{array}$ & \\
\hline & & 3 & $\begin{array}{l}5^{\prime} \text { warm up }+60^{\prime} \text { cycling ( } 15^{\prime} \text { with no gradient }+25^{\prime} \text { with a gradient }+20^{\prime} \text { with } \\
\text { no gradient })+10^{\prime} \text { stretching }\end{array}$ & \\
\hline & \multirow{3}{*}{3} & 1 & $\begin{array}{l}10^{\prime} \text { warm up }+10^{\prime} \text { continuous running (intersperse with gradients) }+10^{\prime} \\
\text { walking (on flat terrain, if possible) }+15^{\prime} \text { continuous running (intersperse with } \\
\text { a gradient, finishing at very low intensity) }+10^{\prime} \text { stretching }\end{array}$ & \\
\hline & & 2 & $\begin{array}{l}5^{\prime} \text { warm up }+50^{\prime} \text { cycling ( } 10^{\prime} \text { with no gradient }+30^{\prime} \text { with a gradient }+10^{\prime} \text { with } \\
\text { no gradient })+10^{\prime} \text { stretching }\end{array}$ & \\
\hline & & 3 & $\begin{array}{l}10^{\prime} \text { warm up }+10^{\prime} \text { continuous running (with a gradient) }+10^{\prime} \text { walking (with no } \\
\text { gradient) }+15^{\prime} \text { continuous running (with a gradient, finishing at very low } \\
\text { intensity) }+10^{\prime} \text { stretching }\end{array}$ & \\
\hline & \multirow{3}{*}{4} & 1 & $\begin{array}{l}10^{\prime} \text { warm up }+15^{\prime} \text { continuous running ( } 10^{\prime} \text { with a gradient) }+5 \text { ' walking (with } \\
\text { no gradient) }+15^{\prime} \text { continuous running (the first } 10^{\prime} \text { with a gradient, finishing at } \\
\text { very low intensity) }+10^{\prime} \text { stretching }\end{array}$ & \\
\hline & & 2 & $\begin{array}{l}5^{\prime} \text { warm up }+60^{\prime} \text { cycling }\left(10^{\prime} \text { with no gradient }+30^{\prime} \text { with a gradient }+10^{\prime} \text { with }\right. \\
\text { no gradient })+10^{\prime} \text { stretching }\end{array}$ & \\
\hline & & 3 & $\begin{array}{c}10^{\prime} \text { warm up }+20^{\prime} \text { continuous running ( } 10^{\prime} \text { with a gradient) }+5 \text { ' walking (with } \\
\text { no gradient) }+20^{\prime} \text { continuous running (the first } 15^{\prime} \text { with a gradient, finishing } \\
\text { at very low intensity) }+10^{\prime} \text { stretching }\end{array}$ & \\
\hline
\end{tabular}

\section{Data analysis}

The data were compiled in an Excel spreadsheet, recording age, height, weight, BMI calculation, IPAQ-SF responses, and participant affiliations. Once the aforementioned information had been collected, the data were entered into SPSS Statistics V.22 program to be examined in the manner described in the results section. 


\section{RESULTS}

The Shapiro-Wilk test was initially carried out to test the normal distribution of the data for each of the variables, verifying that all of them yielded an asymptotic significance value greater than 0.05 . Once the goodness of fit of the data had been checked, a descriptive analysis and $t$-test for related samples were undertaken to determine whether there were significant differences in the variables studied after the treatment (Table 3).

Table 2. Descriptive statistics (mean \pm standard deviation) and comparison of anthropometric variables $(\mathrm{n}=20)$.

\begin{tabular}{lccc}
\hline & Pretest & Posttest & p \\
\hline Weight $(\mathrm{kg})$ & $88.29 \pm 12.41$ & $86.52 \pm 12.62$ & 0.019 \\
Height $^{*}(\mathrm{~cm})$ & \multicolumn{1}{c}{$173.71 \pm 7.43$} & & \\
BMI $\left(\mathrm{kg} / \mathrm{m}^{2}\right)$ & $29.22 \pm 3.48$ & $28.64 \pm 3.54$ & 0.018 \\
Total body fat $(\mathrm{kg})$ & $26.43 .01 \pm 7.76$ & $25.21 \pm 9.04$ & 0.024 \\
Total body fat $(\%)$ & $29.35 \pm 5.48$ & $28.11 \pm 6.64$ & 0.014 \\
\hline
\end{tabular}

${ }^{*}$ As the participants had completed their growth stage, their height was evaluated at the beginning of the experimental phase only, and therefore it was not necessary to make a comparison. Significance value of $p>0.05$.
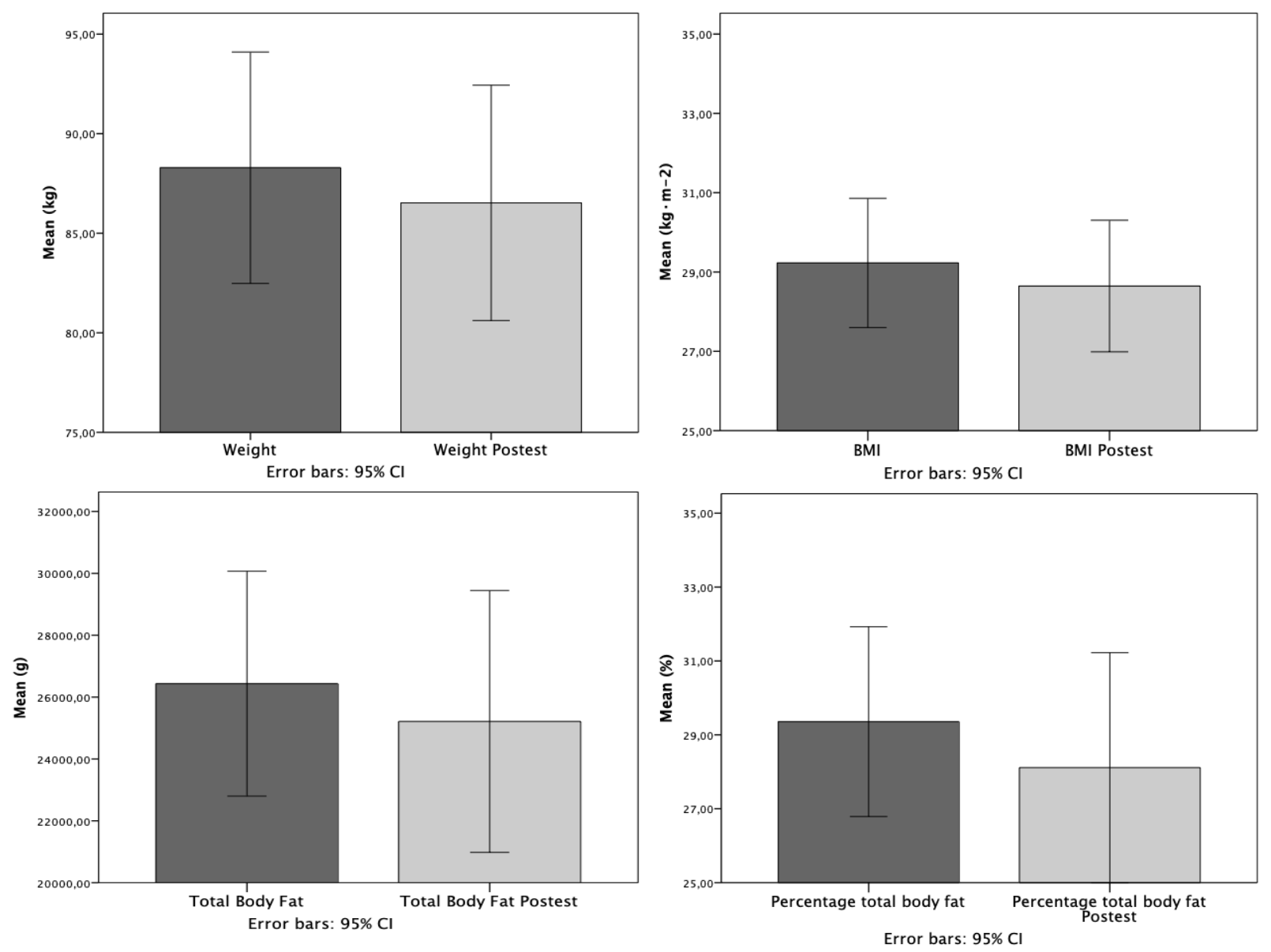

Figure 1. Evolution of the anthropometric study variables before and after aerobic exercise treatment. 
Figure 1 shows that the study participants were able to improve in all the values studied with statistically significant differences. It should be noted that the weight lost approached the amount of body fat lost.

The following table shows the changes in energy expenditure before and after the treatment during the experimental phase.

Table 3. Descriptive and comparative statistics (mean \pm standard deviation) of the METS ( $n=20)$

\begin{tabular}{lccc} 
& Pretest & Posttest & $p$ \\
\hline METS min/week vigorous & $980.87 \pm 953.60$ & $4038.26 \pm 1821.55$ & .000 \\
METS min/week moderate & $450.44 \pm 497.41$ & $1615.65 \pm 850.98$ & .000 \\
METS min/week walking & $949.25 \pm 1224.36$ & $1336.50 \pm 804.70$ & .212 \\
METS min/week totals & $2380.56 \pm 1780.80$ & $6690.42 \pm 2426.89$ & .000 \\
\hline
\end{tabular}
Significance is $p>0.05 ; \mathrm{min} /$ week $=$ minutes per week.

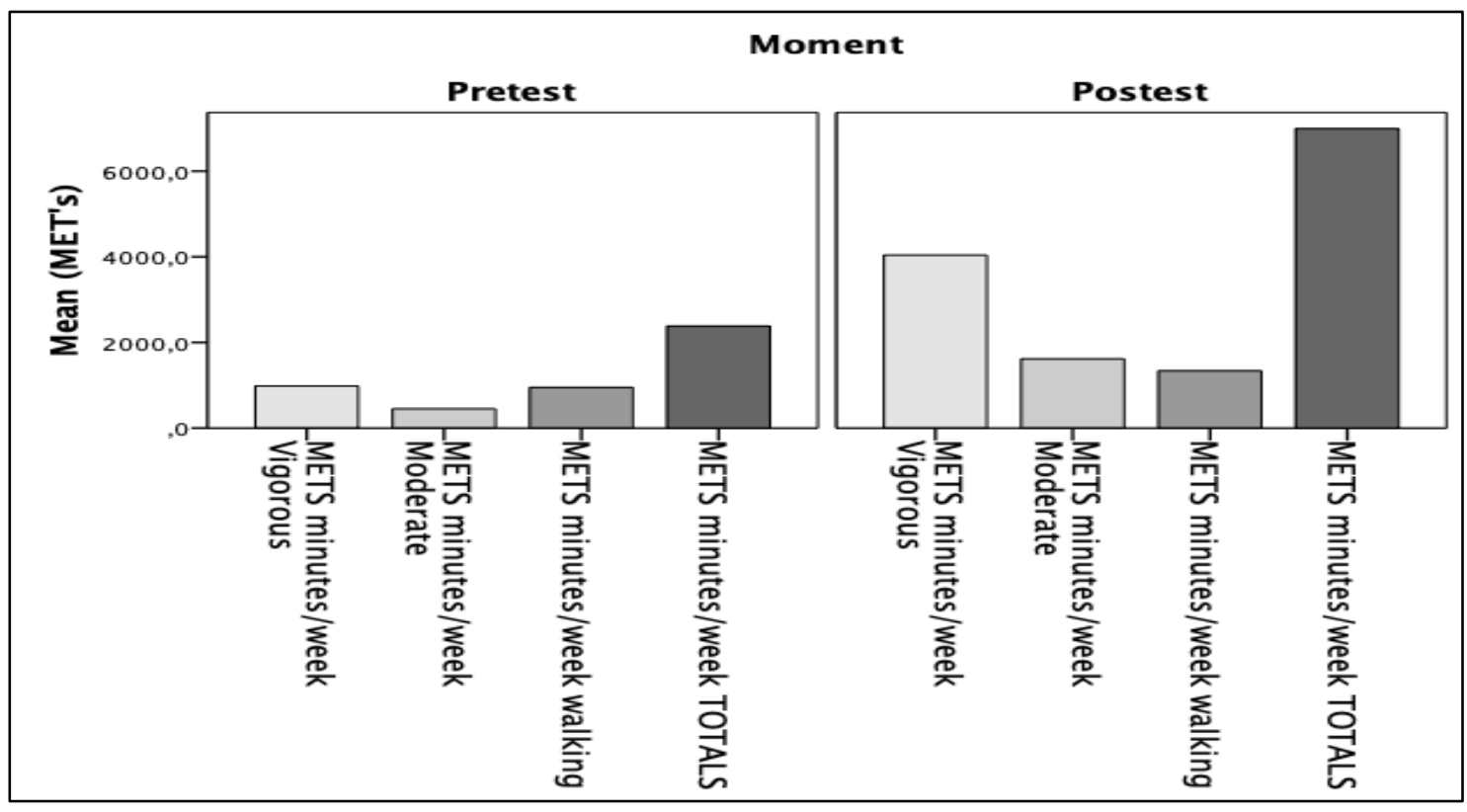

Figure 2. Number of vigorous, moderate, walked and total METS.

It can be observed that after treatment there is a considerable increase not only in total METS (more than 4000), but also in moderate METS (more than 1000) and vigorous METS (more than $3000 \mathrm{METS}$ ). As shown in both Table 3 and Figure 2, walking METS also increase but not significantly $(p=0.212)$.

The IPAQ-SF makes it possible to quantify physical activity through the MET minutes/week indicator, which represents energy expenditure and classifies physical activity as follows: high: achieving a minimum of 3000 MET-min/week or at least $1500 \mathrm{MET}$-min/week in vigorous activity only; moderate: achieving at least 600 MET-min/week; and low: achieving less than $600 \mathrm{MET}$-min/week. Therefore, as shown in Table 3 and Figure 2, vigorous METs rise from moderate to high, moderate METs rise from low to moderate, while walking METS remain moderate, and total MET computation rises from moderate to vigorous total activity. 


\section{DISCUSSION}

At present, obesity continues to be a worldwide public health problem. Paradoxically, PA is a preventive, therapeutic, easy and economic measure that is potentially capable of reducing this social problem. Furthermore, all patients who are overweight or obese, apart from specific exceptions, may participate in a PA program, although few do so (Catenacci, et al. 2007). Bouchard et al. (2012), point out that PA and sports contribute from $25 \%$ to $50 \%$ of total daily energy expenditure. Therefore, the inclusion of PA on a regular basis is the most important intervention to be implemented to promote weight loss in overweight or obese patients.

Our study, which conducted a twelve-week training program of aerobic exercise only, revealed high levels of moderate and vigorous physical activity in overweight or obese young adults. The results indicate that the study participants had high adherence to the training program and, as in other studies, their energy expenditure increased (Gastin et al., 2018; Ostendorf et al., 2019) causing a decrease in percentage of total body fat, as well as in body weight and BMI. These results are in line with those of Abilleira-González et al., (2018) who implemented a twelve-week aerobic training program in obese university students, finding improvements only in fat mass loss, as well as the study by Sillanpää et al. (2008) and Eklund et al. (2016) who used mixed training with two and three weekly sessions, respectively, showing statistically significant improvements in fat mass and weight loss.

As indicated by Haskell et al. (2007), the IPAQ-SF enables accurate determination of energy expenditure levels and, therefore, we can conclude that the participants in our experiment significantly increased their energy expenditure in both vigorous and moderate activities and, as a consequence, in the total physical activity carried out. It should also be pointed out that the benefits of this program can be attributed to moderate and vigorous activities, as the METS used in walking before and after treatment showed no significant differences.

It should be noted that the few previous studies in this field used mixed programs that were not solely focused on aerobic work, and very few of these used the IPAQ-SF to measure PA levels. Use of the IPAQ-SF is one of the main contributions of our study, together with the singular nature of the participation of young adults, which is a population that has been very little studied.

\section{CONCLUSION}

A statistically significant improvement was found in the different variables studied. These included weight loss, fat mass, percentage of body fat and BMI. In addition, energy expenditure increased significantly, with a very significant increase in the number of METS, especially the intense, moderate and consequently the total METS minutes/week.

A line of research should be opened in this population segment that has been so little studied, particularly considering the high sensitivity shown by the results of the participants after only twelve weeks of aerobic resistance training.

\section{REFERENCES}

Abilleira-González, M., Fernández-Villarino, M.A., Varela-Casal, C., Arufe-Giráldez, V., Silva-Piñeiro, R., \& Gonzalez-Gonzalez, S.G. (2018). Physical activity intervention program through walking routes in 
sedentary university students. Journal of Human Sport and Exercise, in press. https://doi.org/10.14198/ihse.2019.142.13

Börg, G. (1982). Psychophysical bases of perceived exertion. Medicine Science in Sports Exercise, 14(5), 337-381. https://doi.org/10.1249/00005768-198205000-00012

Bouchard, C., Blair, S.N., Haskell, W.L. (2012). Physical Activity and Health. Human Kinetics Publishers; Edition: 2nd Revised edition.

Bull, F. C., Maslin, T. S., \& Armstrong, T. (2009). Global physical activity questionnaire (GPAQ): nine country reliability and validity study. Journal of Physical Activity \& Health, 6(6), 790-804. https://doi.org/10.1123/jpah.6.6.790

Carrera, Y. (2017) Cuestionario Internacional de actividad física. Revista Enfermería del Trabajo, 7(2), 49-54.

Craig, CL; Marshall, AL, Sjostrom M; Bauman AE; Booth, ML; Ainsworth BE. (2003). International Physical Activity Questionnaire: 12-country reliability and validity. Med Sci Sports Exerc, 35(8), 1381-1395. https://doi.org/10.1249/01.mss.0000078924.61453.fb

Catenacci, V. A., \& Wyatt, H. R. (2007). The role of physical activity in producing and maintaining weight loss. Nature Clinical Practice Endocrinology \& Metabolism, 3(7), 518-529. https://doi.org/10.1038/ncpendmet0554

Chor, D., Oliveira Cardoso, L., Araújo Nobre, A., Härter Griep, R., Mendes Fonseca, M.d.J., Giatti, L., Bensenor, I., et al., (2016). Association between Perceived Neighbourhood Characteristics, Physical Activity and Diet Quality: Results of the Brazilian Longitudinal Study of Adult Health (ELSA-Brasil). BMC Public Health, 16 (1), 751-761. https://doi.org/10.1186/s12889-016-3447-5

Drenowatz, C., Hill, J., Peters, J., Soriano-Maldonado, A., Blair, S. (2017). The association of change in physical activity and body weight in the regulation of total energy expenditure. European Journal of Clinical Nutrition, 71(3), 377-382. https://doi.org/10.1038/ejcn.2016.228

Eklund, D., Schumann, M., Kraemer, W. J., Izquierdo, M., Taipale, R. S., Häkkinen, K. (2016). Acute Endocrine and Force Responses and Long-Term Adaptations to Same-Session Combined Strength and Endurance Training in Women. Journal of Strength and Conditioning Research, 30(1), 164-175. https://doi.org/10.1519/jsc.0000000000001022

Gastin, P. B., Cayzer, C., Dwyer, D., \& Robertson, S. (2018). Validity of the ActiGraph GT3X+ and BodyMedia SenseWear Armband to estimate energy expenditure during physical activity and sport. Journal of Science and Medicine in Sport, 21(3), 291-295. https://doi.org/10.1016/j.jsams.2017.07.022

Guedes, Dartagnan Pinto, \& Gonçalves, Leandro A.V. Verde. (2007). Impacto da prática habitual de atividade física no perfil lipídico de adultos. Arquivos Brasileiros de Endocrinologia \& Metabologia, 51(1), 72-78. https://doi.org/10.1590/s0004-27302007000100012

Haskell, W.L., Lee, I.M., Pate, R.R., Powell, K.E., Blair, S.N., Franklin, B.A., Macera, CA, Heath, GW, Thompson, PD, Bauman, A. (2007) Physical activity and public health: updated recommendation for adults from the American College of Sports Medicine and the American Heart Association. Circulation, 39(8), 1423-34. https://doi.org/10.1249/mss.0b013e3180616b27

Harriss, D. J., Macsween, A., \& Atkinson, G. (2017). Standards for Ethics in Sport and Exercise Science Research: 2018 Update. International Journal of Sports Medicine, 38(14), 1126-1131. https://doi.org/10.1055/s-0043-124001

Jakicic, J. M., King, W. C., Marcus, M. D., Davis, K. K., Helsel, D., Rickman, A. D., ... Belle, S. H. (2015). Short-term weight loss with diet and physical activity in young adults: The IDEA study. Obesity, 23(12), 2385-2397. https://doi.org/10.1002/oby.21241

JAVA. (2013). Declaration of Helsinki World Medical Association Declaration of Helsinki. Bulletin of the World Health Organization. 
Jetté, M., Sidney, K., \& Blümchen, G. (1990). Metabolic equivalents (METS) in exercise testing, exercise prescription, and evaluation of functional capacity. Clinical Cardiology, 13(8), 555-565. https://doi.org/10.1002/clc.4960130809

Lee, P. H., Macfarlane, D. J., Lam, T., \& Stewart, S. M. (2011). Validity of the international physical activity questionnaire short form (IPAQ-SF): A systematic review. International Journal of Behavioral Nutrition and Physical Activity, 8(1), 115. https://doi.org/10.1186/1479-5868-8-115

Moseng, T., Tveter, A. T., Holm, I., \& Dagfinrud, H. (2014). Patients with musculoskeletal conditions do less vigorous physical activity and have poorer physical fitness than population controls: a crosssectional study. Physiotherapy, 100(4), 319-324. https://doi.org/10.1016/i.physio.2013.11.005

Neilson, H. K., Robson, P. J., Friedenreich, C. M., \& Csizmadi, I. (2008). Estimating activity energy expenditure: how valid are physical activity questionnaires? The American Journal of Clinical Nutrition, 87(2), 279-291. https://doi.org/10.1093/ajcn/87.2.279

Ostendorf, D.M., Lyden, K., Pan, Z., Wyatt HR., Hill JO., Melanson EL., Catenacci, VA. (2017). Objectively measured physical activity and sedentary behavior in successful weight loss maintainers. Obesity, 26(1), 53-60. https://doi.org/10.1002/oby.22052

Ostendorf, M. D., Caldwell, E.A., Creasy, A.S., Pan, Z., Layden, K., Bergouignam, A., Maclean, S.P., Wyatt, R.H., Hill, O.J., Melanson, L.E., Catenacci, A.V., (2019). Physical activity energy expenditure and total daily energy expenditure in successful weight loss maintainers. Obesity, 27(3), 496-504. https://doi.org/10.1002/oby.22373

Pitsavos, C., Kavouras, S.A., Panagiotakos, D.B., Arapi, S., Anastasiou, C.A., Zombolos, S., Stravopodis, P., et al., (2008). Physical Activity Status and Acute Coronary Syndromes Survival. J. Am. Coll. Cardiol., 51(21), 2034-2039. https://doi.org/10.1016/j.jacc.2008.01.053

Rodríguez, F., Cristi-Montero, C., Villa-González, E. Solís-Urra, P., Chillón, P. (2018) Comparison of the physical activity levels during the university life. Revista Médica de Chile, 146(4), 442-450. https://doi.org/10.4067/s0034-98872018000400442

Rojas-Gómez, D.M., Giacometto, M., Olmos, C., Arias, V., Muñoz-Carvajal, Y., Pérez-Leighton, C., Núnez-Palma, C., Rojas, R. (2018). Eating behavior and its association with nutritional status and physical activity in a general Chilean population. Nutrición Hospitalaria, 35(6), 1316-1323.

Ross, R., Hudson, R., Stotz, P. J., y Lam, M. (2015). Effects of exercise amount and intensity on abdominal obesity and glucose tolerance in obese adults: a randomized trial. Annals of internal medicine, 162(5), 325-334. https://doi.org/10.7326/m14-1189

Sanda, B., Vistad, I., Haakstad, L. A. H., Berntsen, S., Sagedal, L. R., Lohne-Seiler, H., Torstveit, M. K. (2017). Reliability and concurrent validity of the International Physical Activity Questionnaire short form among pregnant women. BMC Sports Science, Medicine and Rehabilitation, 9, 7. https://doi.org/10.1186/s13102-017-0070-4

Sillanpää, E., Häkkinen, A., Nyman, K., Mattila, M., Cheng, S., Karavirta, L., Laaksonen, DE., Huuhka, N,, Kraemer, WJ., Häkkinen K. (2008). Body composition and fitness during strength and/or endurance training in older men. Medicine and Science in Sports and Exercise, 40(5), 950-958. https://doi.org/10.1249/mss.0b013e318165c854

Swendeman, D., Comulada, W. S., Koussa, M., Worthman, C. M., Estrin, D., Rotheram-Borus, M. J., y Ramanathan, N. (2018). Longitudinal validity and reliability of brief smartphone self-monitoring of diet, stress, and physical activity in a diverse sample of mothers. Journal of Medical Internet Research, 6(9): e176. https://doi.org/10.2196/preprints.9378

Vanhelst, J., Fardy, P. S., Mikulovic, J., Bui-Xuan, G., \& Béghin, L. (2013). Concurrent Validity of the Modified International Physical Activity Questionnaire for French Obese Adolescents. Perceptual and Motor Skills, 116(1), 123-131. https://doi.org/10.2466/03.06.pms.116.1.123-131 
World Health Organization. (2019). Obesity and overweight. Accessed May 1, 2019 at https://www.who.int/es/news-room/fact-sheets/detail/physical-activity 